\title{
Managing atrial fibrillation in the very elderly patient: challenges and solutions
}

\author{
This article was published in the following Dove Press journal: \\ Vascular Health and Risk Management \\ 27 October 2015 \\ Number of times this article has been viewed
}

\author{
Nikolaos Karamichalakis \\ Konstantinos P Letsas \\ Konstantinos Vlachos \\ Stamatis Georgopoulos \\ Athanasios Bakalakos \\ Michael Efremidis \\ Antonios Sideris \\ Laboratory of Cardiac \\ Electrophysiology, "Evangelismos" \\ General Hospital of Athens, \\ Athens, Greece
}

Correspondence: Konstantinos P Letsas Laboratory of Cardiac Electrophysiology, "Evangelismos" General Hospital of Athens, Athens 10676, Greece

Fax +30 2I 3204 I344

Email k.letsas@mail.gr

\begin{abstract}
Atrial fibrillation (AF) is the most common arrhythmia affecting elderly patients. Management and treatment of AF in this rapidly growing population of older patients involve a comprehensive assessment that includes comorbidities, functional, and social status. The cornerstone in therapy of AF is thromboembolic protection. Anticoagulation therapy has evolved, using conventional or newer medications. Percutaneous left atrial appendage closure is a new invasive procedure evolving as an alternative to systematic anticoagulation therapy. Rate or rhythm control leads to relief in symptoms, fewer hospitalizations, and an improvement in quality of life. Invasive methods, such as catheter ablation, are the new frontier of treatment in maintaining an even sinus rhythm in this particular population.
\end{abstract}

Keywords: elderly, atrial fibrillation, anticoagulation, drugs, catheter ablation

\section{Introduction}

Atrial fibrillation (AF) prevalence increases with age, making it the most common arrhythmia in patients older than 65 years. For patients older than 80 years, the corresponding rate is approximately $10 \%{ }^{1}$ Furthermore, $70 \%$ of individuals with AF are between the age of 65 and 85 years. $^{2}$ The prevalence of AF is increasing in parallel to the aging of the population. ${ }^{3} \mathrm{AF}$ itself cannot be considered directly life threatening, but it is undoubtedly related to an increased risk of death. In the Framingham cohort, the total mortality odds ratio was 1.5 for male and 1.9 for female patients with AF, even after adjustment for age and other risk factors. ${ }^{4}$ In addition, the morbidity of the elderly patients suffering from AF is of considerable importance, because these patients exhibit increased and, often, long hospitalizations due to heart failure, strokes, need for pacemaker implantations, and adverse effects related to antiarrhythmic therapy. Even though this arrhythmia has been acknowledged since the ancient civilizations of China, Egypt, and Greece, ${ }^{5}$ and its treatment and management remain a challenge to the modern day physician. Recent breakthroughs in drug therapy and invasive techniques have opened new horizons in the field of AF. Elderly patients who were previously excluded from trials are now actively participating in various studies, thus giving medical science new solutions concerning the management and treatment of this age group. This review highlights the management of AF in the very elderly patients.

\section{Classification of AF}

AF is classified as paroxysmal, persistent, longstanding persistent, and permanent. ${ }^{6}$ Paroxysmal AF is defined as recurrent AF (two episodes) that terminates spontane- 
ously within 7 days. Episodes of AF of 48 hours duration that are terminated with electrical or pharmacologic cardioversion should also be classified as paroxysmal AF episodes. Persistent AF is defined as continuous AF that is sustained beyond 7 days. Episodes of AF in which a decision is made to electrically or pharmacologically cardiovert the patient after 48 hours of AF, but prior to 7 days, should also be classified as persistent AF episodes. Longstanding persistent $\mathrm{AF}$ is defined as continuous AF of greater than 12 months duration. The term permanent AF is not appropriate in the context of patients undergoing catheter or surgical ablation of AF, as it refers to a group of patients for which a decision has been made not to restore or maintain sinus rhythm by any means, including catheter or surgical ablation. If a patient previously classified as having permanent AF is to undergo catheter or surgical ablation, the AF should be reclassified.

\section{Pathophysiology of AF}

Aging heart, characterized by myocardial fibrosis and atrial dilation, is a proper soil for AF to flourish. AF creates electrical and structural remodeling in the atria by shortening, mismatching, and lengthening the effective refractory period (increase of dispersion), depressing the intra-atrial conduction, and depriving its contractile function. Thus, "AF begets AF". ' Structural heart disease enforces atrial chamber abnormality, and this explains the higher prevalence of AF in patients with underlying cardiovascular conditions. ${ }^{8,9}$ Such conditions are valvular heart disease, hypertension, ischemic cardiomyopathy, dilated cardiomyopathy, and hypertrophic cardiomyopathy. Other less common causes are restrictive cardiomyopathies such as amyloidosis, constrictive pericarditis, cardiac tumors, and severe pulmonary hypertension. ${ }^{10}$ Obstructive sleep apnea and obesity are independent risk factors for AF. ${ }^{11,12}$ The electrical and structural remodeling determines the perpetuation of AF and the progression from paroxysmal to persistent and permanent forms. The longer one waits to initiate a rhythm treatment strategy, the more difficult it is to regain sinus rhythm.

\section{Diagnosis of AF}

A single 12-lead electrocardiogram (ECG) is more than enough to set the diagnosis of AF. Because the elderly patients are often asymptomatic, AF is frequently a random finding. ${ }^{13}$ If AF is suspected, repeated ECGs or ambulatory monitoring is advised. In the case of first-diagnosed AF, diagnostic evaluation should further continue with chest X-ray, transthoracic, or transesophageal echocardiography and blood tests, including thyroid hormones. ${ }^{14}$

\section{Management and treatment}

The goals in the treatment and management of AF are, first, to prevent thromboembolic episodes, mainly strokes, which leads to a considerable reduction in mortality, and second, to improve the quality of life, by reducing the symptoms and hospitalizations. The first goal is achieved using anticoagulant therapy, and the second is achieved through rhythm or rate control. Newer techniques such as catheter ablation are rapidly establishing their role in treatment.

\section{Anticoagulation therapy in elderly patients}

Elderly patients should be administered anticoagulation therapy for AF. Both CHADS2 and the newer CHA2DS2VASc scores ${ }^{15,16}$ emphasize the importance of increased age in the evaluation of thromboembolic risk. Patients with CHADS2 $\geq 2$ should receive oral anticoagulation (OAC). ${ }^{15}$ Patients with score 1 are subject to the physician's opinion to receive anticoagulants or aspirin. Using the newer CHA2DS2VASc score, all patients older than 75 years should receive OAC, unless there is a strong contraindication. ${ }^{16}$ The ATRIA $^{1}$ and BAFTA ${ }^{17}$ studies have shown that elderly patients with AF benefited by the use of anticoagulation therapy. OACs have reduced the thromboembolic risk in these patients when compared to aspirin. ${ }^{1,17}$ The OACs used in these studies were vitamin $\mathrm{K}$ antagonists (VKAs), especially warfarin. Maintaining an international normalized ratio (INR) between 2.0 and 3.0 is the target for thromboembolic protection. INR values more than 3.0 have not shown any advantage; on the other hand, they raised the risk of bleeding. The revised guidelines by Japanese Circulation Society (JCS) suggest a target INR of 1.6-2.6 for patients with nonvalvular AF and aged $\geq 70 .{ }^{18}$ INR should be monitored regularly, even if the patient is stable, and every one of them must keep an INR diary. VKAs were traditionally and incorrectly underused in the elderly patients by the physicians, fearing that this subgroup of patients would be eventually neglected and that INR monitoring would be skipped. Elderly patients are prone to injuries and falls, and thus the fear of bleeding is considerable in them. The HAS-BLED ${ }^{19}$ and HEMMORR2HAGES ${ }^{20}$ scores are valuable tools in evaluating these patients' bleeding risk. VKAs are connected to serum albumin. In the elderly patients, serum albumin levels often drop dramatically due to inflammation or malnutrition and lack of protein in their diets. ${ }^{21}$ VKA overdose is frequent in these situations and hence INR should be monitored closely, every 15-21 days.

Novel oral anticoagulants (NOACS), on the contrary, do not require INR monitoring and are rapidly getting popular 
even among the elderly. NOACS currently used in clinical practice include dabigatran which is a direct thrombin inhibitor, and rivaroxaban, apixaban, and edoxaban which are direct factor Xa inhibitors. Dabigatran at a dosage of $110 \mathrm{mg}$ twice daily showed a reduced cerebral hemorrhage risk in the patients over 75 years old, but still maintained a smaller risk for thromboembolic events versus warfarin. However, at a dose of $150 \mathrm{mg}$ twice daily, the risk of major bleeding was higher compared to VKAs and was found to increase with age. ${ }^{22}$ Due to its renal elimination, dabigatran should be handled cautiously in patients with renal impairment and should be strongly contraindicated if creatinine clearance is below $30 \mathrm{~mL} / \mathrm{min}^{23}$ Rivaroxaban in patients over 75 years old has shown noninferiority in comparison to warfarin in thromboembolic protection, as seen in the ROCKET-AF trial. Patients receiving rivaroxaban presented less intracranial hemorrhages and fatal bleeding. ${ }^{24}$ These results applied even in the subgroup with moderate renal failure (clearance $30-49 \mathrm{~mL} / \mathrm{min}$ ). In such patients, the dosage of $15 \mathrm{mg}$ once per day is suggested. Rivaroxaban is also contraindicated if creatinine clearance is below $30 \mathrm{~mL} / \mathrm{min}$. The AVERROES trial, which compared apixaban versus aspirin in patients who could not receive VKAs, was stopped because it showed clear superiority for apixaban. ${ }^{25}$ Apixaban, administered $5 \mathrm{mg}$ twice daily, was compared to warfarin in the ARISTOTLE trial. In the subgroup of patients over 75 years old, apixaban was more beneficial than warfarin in terms of thromboembolic protection and major bleeding events. ${ }^{26}$ The dosage of $2.5 \mathrm{mg}$ twice daily was administered to patients with two of the three following criteria: age $\geq 80$ years, weight $\leq 60 \mathrm{~kg}$, and serum creatinine $\geq 133 \mu \mu \mathrm{mol} / \mathrm{L}$. Apixaban must not be administered in patients displaying creatinine clearance less than $30 \mathrm{~mL} / \mathrm{min}$. Edoxaban is administered once daily and has a renal excretion of $50 \%$. In the Engage AF TIMI 48 trial, patients over 75 years of age receiving edoxaban in the highest dosage presented a reduction in strokes and other thromboembolic events, but also an increase in major bleeding events. On the other hand, the subgroup over 75 years old receiving low-dose edoxaban showed results similar to the warfarin group. ${ }^{27} \mathrm{~A}$ recent meta-analysis showed that NOACS, compared to warfarin, lead to a significant reduction in strokes, intracranial hemorrhages, mortality, and comparable major bleeding events. ${ }^{28}$ Their safety and relative efficiency have been consistent throughout a wide range of age groups including the elderly. They have fewer interactions with other drugs, they do not interact with food as VKAs do, and they present a rapid onset of action. However, they are related to a rise in gastrointestinal bleedings, their cost is considerable, and their effects are still difficult to reverse. ${ }^{28}$

OAC therapy in elderly patients with AF and coronary artery disease (CAD) is challenging. In patients 75 years or older with AF after an acute coronary syndrome and revascularization, triple antithrombotic therapy (aspirin, clopidogrel plus oral anticoagulant) for a minimum of 4 weeks and up to a maximum of 6 months should be administered. Because of the high risk of bleeding in the elderly, the duration of this therapy should not last more than 4 weeks, and bare metal stent should be selected. Afterward, patients will continue treatment with dual therapy (antiplatelet agent plus oral anticoagulant) for 1 year. In such a case, clopidogrel plus VKA seems to have a better hemorrhagic profile than clopidogrel plus acetylsalicylic acid plus VKA, with no inferiority to stent thrombosis. ${ }^{29}$ Patients 75 years or older with AF with stable CAD who underwent revascularization should receive triple therapy for 2-4 weeks and proceed to dual therapy for 1-12 months. Bare metal stenting should be preferred in such a case also. In patients without a revascularization procedure, a single treatment with VKAs or NOAC seems to be sufficient. It should be noted that newer antiplatelets are not yet approved in triple therapy and prasugrel is contraindicated in patients aged 75 and over. ${ }^{29}$

\section{Percutaneous left atrial appendage closure}

As mentioned earlier, many patients, particularly the elderly, cannot tolerate or even refuse to receive chronic anticoagulation therapy. As an alternative to systemic anticoagulation, a new invasive procedure has been evolved, the percutaneous left atrial appendage (LAA) closure. Approximately 90\% of the left atrial thrombi originate from the LAA, and its successful occlusion can significantly reduce the thromboembolic risk. Patients with nonvalvular AF, at high stroke risk and contraindications for OACs are possible candidates for this technique. ${ }^{30}$ Contraindications to anticoagulants among others include acute clinically significant bleeding, gastrointestinal diseases such as esophageal varices, insufficiently treated neoplasms, peptic ulcer within last 3 months, decompensated liver disease or deranged baseline clotting screening, and hematological disorders such as unexplained and untreated anemia, myelodysplastic syndrome, and severe thrombocytopenia. Additional contraindications are vascular diseases or malformations, previous history of intracranial hemorrhage, and a high probability of injuries and traumas such as epilepsy, frequently noted in the elderly. ${ }^{30,31}$ 
Over the latest years, various percutaneous techniques and suitable devices have been used for LAA closure. Despite the promising long-term results, the initial device used for LAA closure (PLAATO, Medtronic, Mansfield, MA, USA) was pulled off the market. ${ }^{32}$ In the PROTECT AF trial, the Watchman device (Boston Scientific, Marlborough, MA, USA) has been proven to be noninferior to warfarin regarding stroke risk, systematic embolism, and cardiovascular death and superior to warfarin for hemorrhagic stroke. ${ }^{33}$ Then again, patients undergoing device implantation showed a four times higher complication risk, the most common risk being pericardial effusion. The mean age of the patients participating in the study was 71.7 years in the device arm and 72.7 years in the warfarin arm. In the PROTECT AF trial, the device arm received warfarin for 6 weeks after implantation. ${ }^{33}$ After discontinuation of warfarin, clopidogrel and aspirin were administered for 6 months. Patients need to receive aspirin indefinitely. The ASAP study was designed to test the efficacy and safety of LAA closure in patients improper for warfarin administration. ${ }^{34}$ Patients recruited for the study only received antiplatelet agent after implantation and had a mean age of $72.5 \pm 7.4$ years. The main reason for warfarin ineligibility was history of hemorrhagic/bleeding tendencies. The ASAP study proved that LAA closure with the Watchman device could be safely performed without systemic OAC. ${ }^{34}$ The Amplatzer Cardiac Plug (St Jude, Minneapolis, MN, USA) is a similar device with excellent results, but it has not been approved by the Food Drug Administration for LAA closure yet. ${ }^{35,36}$ Implantation of the Lariat device (SentreHEART, Redwood City, CA, USA) requires closing a strangling noose around the LAA, advanced from the chest wall with a special sheath, after introducing a balloon in the LAA from the endocardium. ${ }^{37}$ Newer devices, currently under investigation, are the Transcatheter Patch (Custom Medical Devices, Athens, Greece), AEGIS (AEGIS, Vancouver, Canada), and the Coherex WaveCrest (Coherex Medical, Salt Lake City, UT, USA). ${ }^{38}$ Patients with AF at high stroke risk and with contraindications for OAC should be considered as candidates for LAA closure. Elderly patients often present these characteristics and could benefit from this novel therapy.

\section{Antiarrhythmic drugs in elderly patients Rate control}

In the elderly patients, especially the asymptomatic ones, rate control is the first-line therapy. ${ }^{30}$ As shown in the AFFIRM substudy, $\beta$-blockers are the most effective at achieving that goal. ${ }^{39}$ Nondihydropyridine calcium channel blockers (verapamil and diltiazem) can be administered as an alternative. Digoxin is recommended in acute heart failure, ${ }^{30}$ but has been proven to be an independent risk factor for death in patients without heart failure and should be used cautiously in the elderly in whom renal function is delicate. ${ }^{40}$ Amiodarone can also be used for rate control, but has considerable extracardiac side effects. ${ }^{41,42}$ Strict rate control does not seem to improve morbidity and mortality, ${ }^{43}$ and so appropriate use of these drugs is recommended in order to avoid excess bradycardia or atrioventricular block.

\section{Rhythm control}

In an elderly patient with recurrences of AF despite receiving rhythm control medication, further attempts at restoring sinus rhythm are not suggested. Cardioversion, whether electrical or pharmaceutical, is related to serious side effects in the elderly and unless $\mathrm{AF}<48$ hours, and $\mathrm{OAC}$ must be documented for at least 3 weeks. Electrical cardioversion requires anesthesia, while pharmaceutical cardioversion requires medication that has serious side effects and contraindications. Amiodarone is the safest choice in pharmaceutical cardioversion in the elderly. As featured in major studies, no significant difference in survival was found using rhythm or rate control in patients older than 65 years with at least one stroke risk factor. ${ }^{30,39,44}$ While there is a wide range of antiarrhythmic agents used to maintain sinus rhythm, in the elderly, there are limitations because of their coexisting heart, renal, or hepatic diseases. Antiarrhythmic agents have been associated with serious adverse side effects, particularly the induction of proarrhythmia. Proarrhythmia, caused by class I and III agents, is manifested as a rise in ventricular ectopy, QT interval prolongation, polymorphic ventricular tachycardia (torsades de pointes), monomorphic ventricular tachycardia, or excess bradycardia. Studies have shown that quinidine, flecainide, sotalol, and dofetilide are the antiarrhythmics most prone to ventricular proarrhythmia. ${ }^{45,46}$ Class I antiarrhythmic drugs are generally not recommended in the elderly. Class Ia agents, including quinidine, procainamide, and disopyramide, are not used anymore for the prevention of $\mathrm{AF}^{42}$ As observed in the CAST study, ${ }^{47}$ flecainide, among other Ic drugs, increased mortality in comparison to placebo, in patients who suffered myocardial infraction. Therefore, flecainide and propafenone must be given to patients without structural heart disease. Administration of these drugs to the elderly must be performed cautiously, given the high probability of underlying CAD. When administered in outpatients, QRS duration must be monitored closely: QRS widening must not exceed $150 \%$ of the baseline QRS. ${ }^{6}{ }^{15}$ Exercise testing should be performed 
1 or 2 weeks after initiation, as it may disclose QRS widening at high rates, or exercise-induced proarrhythmia. ${ }^{6,15,30,42}$ In the case of CAD without heart failure, sotalol, dofetilide, amiodarone, and dronedarone (class III antiarrhythmic agents) can be used for maintaining sinus rhythm. ${ }^{6,15,30,42}$ Dronedarone should be given cautiously to the elderly. ${ }^{48}$ The PALLAS study has shown that dronedarone has been related to an increased risk of cardiovascular events in the following groups of patients: 1) 65 years or older with permanent $A F$ and either CAD, previous stroke, or heart failure and 2) 75 years or older with hypertension and diabetes. ${ }^{48}$ Patients with AF and heart failure or left ventricular dysfunction are limited to amiodarone and dofetilide. Those with substantial left ventricular hypertrophy (left ventricular wall thickness $\geq 13 \mathrm{~mm}$ ) can only receive amiodarone. ${ }^{6,15}$ When class III agents are administered, QTc interval must be monitored and must remain below $520 \mathrm{~ms}$. In any case of antiarrhythmic drug use, follow-up must include measurement of serum creatinine, potassium, and magnesium regularly. Renal impairment can increase proarrhythmia and also requires dosage adjustment of dofetilide and sotalol. ${ }^{6,15,30,42}$

\section{Catheter ablation of AF in the elderly}

Left atrial catheter ablation has lately proven to be a considerable therapeutic option in maintaining sinus rhythm in patients suffering from AF. ${ }^{49}$ However, AF catheter ablation has not been yet commonly established in the elderly population. ${ }^{30}$ Due to concerns about efficacy and safety of this method, patients aged 75 years and over were previously excluded from many catheter ablation trials. ${ }^{50,51}$ So far, the main volume of data concerning the safety and efficacy of left atrial ablation has been derived from studies and trials focused on younger patients without heart disease or comorbidities. ${ }^{52}$ Catheter ablation is strongly contraindicated in patients with thrombus in the left atrium or in patients who cannot receive anticoagulation for at least 6-8 weeks after the procedure. In a large worldwide survey, major complications of catheter ablation, including death, cardiac tamponade, strokes, and transient ischemic attacks were reported in $4.5 \%$ of cases. ${ }^{53}$ Then again, rate control strategy in the elderly may induce extreme bradycardia, while antiarrhythmic drugs used to achieve rhythm control are prone to proarrhythmia and drug interactions.

Evolution in AF ablation techniques and improved efficacy have given the elderly patients an alternative treatment for $\mathrm{AF}^{54}$ Recent studies, including our experience, have demonstrated similar rates of success and adverse events using radiofrequency catheter ablation between the elderly and younger patients. ${ }^{55-61}$ Table 1 summarizes the main findings of these studies. There are some obvious disadvantages of this method. Some patients may relapse and so a second procedure will be required in order to maintain normal sinus rhythm. ${ }^{62}$ Also, the need for anticoagulation ${ }^{63}$ and detection of asymptomatic AF episodes ${ }^{61}$ will have to be further evaluated. Cryoballoon ablation also seems to be a promising technique. The main advantage over radiofrequency ablation

Table I Summary of studies addressing the role of catheter ablation of AF in the elderly patients

\begin{tabular}{|c|c|c|c|c|c|c|}
\hline Study & $\begin{array}{l}\text { Number of } \\
\text { patients }\end{array}$ & Technique & AF type & $\begin{array}{l}\text { Compared age } \\
\text { groups (years) }\end{array}$ & $\begin{array}{l}\text { Success } \\
\text { rate }(\%)\end{array}$ & $\begin{array}{l}\text { Major complications } \\
\text { in the elderly (\%) }\end{array}$ \\
\hline \multirow[t]{3}{*}{ Zado et al ${ }^{55}$} & 32 & PVI plus ablation & PAF & $<65$ & 89 & 2.9 \\
\hline & & of focal sources & PersAF & $65-74$ & 84 & \\
\hline & & & & $>75$ & 86 & \\
\hline \multirow[t]{3}{*}{ Bhargava et $\mathrm{al}^{56}$} & 103 & PVI & PAF & $>60$ & 82 & 3 \\
\hline & & & PersAF & $5 I-60$ & 83 & \\
\hline & & & PermAF & $<50$ & 85 & \\
\hline \multirow[t]{2}{*}{ Kusumoto et $\mathrm{al}^{57}$} & 61 & PVI & PAF & $>75$ & 61 & 0 \\
\hline & & & PersAF & $65-75$ & 84 & \\
\hline \multirow[t]{3}{*}{ Tan et $\mathrm{al}^{58}$} & 49 & PVAI & PAF & $>80$ & 70 & 0.04 \\
\hline & & & PersAF & $70-79$ & 72 & \\
\hline & & & PermAF & $60-69$ & 74 & \\
\hline \multirow[t]{2}{*}{ Bunch et $a^{59}$} & 35 & PVAI plus & PAF & $>80$ & 75 & 0.057 \\
\hline & & linear lesions & PersAF & $<80$ & 78 & \\
\hline \multirow[t]{3}{*}{ Liu et $\mathrm{a}^{60}$} & 2,970 & PVAI & PAF & $>60$ & 77 & 4.53 \\
\hline & & & PersAF & $>60$ & 79 & \\
\hline & & & PermAF & & & \\
\hline \multirow[t]{2}{*}{ Lioni et $\mathrm{a}^{|6|}$} & 95 & PVAI & PAF & $\geq 65$ & 58 & 3.2 \\
\hline & & & & $<65$ & 67 & \\
\hline
\end{tabular}

Abbreviations: AF, atrial fibrillation; PAF, paroxysmal atrial fibrillation; PersAF, persistent atrial fibrillation; PermAF, permanent atrial fibrillation; PVI, pulmonary vein isolation; PVAI, pulmonary vein antral isolation. 
is the lower risk of pulmonary stenosis or esophageal injury. The most common complication of the latter technique is phrenic nerve palsy. ${ }^{64}$

Atrioventricular node (AVN) ablation and pacemaker implantation is a last resort treatment in the elderly patients, especially the highly symptomatic ones. As shown in the PABA-CHF study, left atrial catheter ablation was superior to AVN ablation with biventricular pacing in patients with heart failure who had drug-refractory AF. ${ }^{65}$ Hsieh et al ${ }^{66}$ compared the long-term results of elderly patients with medically refractory paroxysmal AF to either AVN ablation plus single-chamber pacemaker or catheter ablation of AF. ${ }^{66}$ AF was better controlled in the group with AVN ablation and pacemaker implantation than in the group with AF ablation. ${ }^{66}$ However, AVN ablation and pacemaker implantation was associated with a higher incidence of persistent AF and heart failure than catheter ablation of AF in the very long-term follow-up.

\section{Upstream therapies}

Angiotensin-converting enzyme inhibitors, angiotensin receptor blockers, statins, and omega-3 polyunsaturated fatty acids have been related to a reduction in the relative risk in AF. Angiotensin-converting enzyme inhibitors and angiotensin receptor blockers display favorable effects on electrical and structural left atrial remodelling. ${ }^{67,68}$ The use of statin seems to prevent the onset of AF after open heart surgery. ${ }^{69}$ The positive results of statins are possibly mediated through their antiinflammatory and antioxidant actions. ${ }^{69}$ Polyunsaturated fatty acids have direct ion channel and anti-inflammatory effects. It is suggested that they can contribute to the prevention of AF when used in combination with an antiarrhythmic drug. ${ }^{70,71}$

\section{Conclusion}

Over the past decades, novel medications and therapies have been administered to the elderly patients with AF. This subgroup of patients who were neglected and undertreated now occupy the center stage. Therapies must be tailored to elderly patients, with particular attention to structural heart disease and renal failure. Elderly patients are at increased risk for thromboembolic events. Thromboembolic protection is therefore of major importance in this population. Newer anticoagulants are increasing in popularity among the elderly patients without renal failure. Elderly patients with contraindications to OAC are possible candidates for percutaneous LAA closure. Left atrial catheter ablation should be considered in symptomatic elderly patients before AVN ablation and pacemaker implantation.

\section{Disclosure}

The authors report no conflicts of interest in this work.

\section{References}

1. Go AS, Hylek EM, Phillips KA, et al. Prevalence of diagnosed atrial fibrillation in adults: national implications for rhythm management and stroke prevention: the Anticoagulation and Risk Factors in Atrial Fibrillation (ATRIA) study. JAMA. 2001;285(18):2370-2375.

2. Kistler P, Sanders P, Fynn S, et al. Electrophysiologic and electroanatomic changes in the human atrium associated with age. $J \mathrm{Am}$ Coll Cardiol. 2004;44:109-116.

3. Lakshminarayan K, Solid CA, Collins AJ, Anderson DC, Herzog CA. Atrial fibrillation and stroke in the general medicare population: a 10-year perspective (1992 to 2002). Stroke. 2006;37(8):1969-1974.

4. Benjamin EJ, Wolf PA, D'Agostino RB, Silbershatz H, Kannel WB, Levy D. Impact of atrial fibrillation on the risk of death: the Framingham Study. Circulation. 1998;98(10):946-952.

5. Fazekas T. The concise history of atrial fibrillation. Orvostort Kozl. 2007;53(3-4):37-68.

6. Wann LS, Curtis AB, Ellenbogen KA, et al. Management of patients with atrial fibrillation (compilation of 2006 ACCF/AHA/ESC and 2011 ACCF/AHA/HRS recommendations): a report of the American College of Cardiology/American Heart Association Task Force on practice guidelines. Circulation. 2013;127(18):1916-1926.

7. Lu Z, Scherlag BJ, Lin J, et al. Atrial fibrillation begets atrial fibrillation: autonomic mechanism for atrial electrical remodeling induced by short-term rapid atrial pacing. Circ Arrhythm Electrophysiol. 2008;1(3):184-192.

8. Burstein B, Nattel S. Atrial fibrosis: mechanisms and clinical relevance in atrial fibrillation. J Am Coll Cardiol. 2008;51(8):802-809.

9. Everett TH 4th, Olgin JE. Atrial fibrosis and the mechanisms of atrial fibrillation. Heart Rhythm. 2007;4(3 Suppl):S24-S27.

10. Xiao Y, Yang KQ, Yang YK, et al. Clinical characteristics and prognosis of end-stage hypertrophic cardiomyopathy. Chin Med J (Engl). 2015; 128(11):1483-1489.

11. Maan A, Mansour M, Anter E, et al. Obstructive sleep apnea and atrial fibrillation: pathophysiology and implications for treatment. Crit Pathw Cardiol. 2015;14(2):81-85.

12. Goudis CA, Korantzopoulos P, Ntalas IV, Kallergis EM, Ketikoglou DG. Obesity and atrial fibrillation: a comprehensive review of the pathophysiological mechanisms and links. J Cardiol. Epub May 7, 2015. doi: 10.1016/j.jjcc.2015.04.002.

13. Dagres N, Nieuwlaat R, Vardas PE, et al. Gender-related differences in presentation, treatment, and outcome of patients with atrial fibrillation in Europe: a report from the Euro Heart Survey on Atrial Fibrillation. JAm Coll Cardiol. 2007;49(5):572-577.

14. Hanon O, Assayag P, Belmin J, et al; French Society of Geriatrics and Gerontology and the French Society of Cardiology. Expert consensus of the French Society of Geriatrics and Gerontology and the French Society of Cardiology on the management of atrial fibrillation in elderly people. Arch Cardiovasc Dis. 2013;106(5):303-323.

15. Fuster V, Rydén LE, Cannom DS, et al; American College of Cardiology; American Heart Association Task Force; European Society of Cardiology Committee for Practice Guidelines; European Heart Rhythm Association; Heart Rhythm Society. ACC/AHA/ESC 2006 guidelines for the management of patients with atrial fibrillation: full text: a report of the American College of Cardiology/American Heart Association Task Force on practice guidelines and the European Society of Cardiology Committee for Practice Guidelines (Writing Committee to Revise the 2001 guidelines for the management of patients with atrial fibrillation) developed in collaboration with the European Heart Rhythm Association and the Heart Rhythm Society. Europace. 2006;8(9):651-745.

16. Lip GY, Nieuwlaat R, Pisters R, Lane DA, Crijns HJ. Refining clinical risk stratification for predicting stroke and thromboembolism in atrial fibrillation using a novel risk factor-based approach. Chest. 2010;137(2):263-272. 
17. Mant J, Hobbs FD, Fletcher K, et al; BAFTA investigators; Midland Research Practices Network (MidReC). Warfarin versus aspirin for stroke prevention in an elderly community population with atrial fibrillation (the Birmingham Atrial Fibrillation Treatment of the Aged Study, BAFTA): a randomised controlled trial. Lancet. 2007; 370(9586):493-503.

18. JCS Joint Working Group. Guidelines for Pharmacotherapy of Atrial Fibrillation (JCS 2013). Circ J. 2014;78(8):1997-2021.

19. Pisters R, Lane DA, Nieuwlaat R, de Vos CB, Crijns HJ, Lip GY. A novel user-friendly score (HAS-BLED) to assess 1-year risk of major bleeding in patients with atrial fibrillation: the Euro Heart Survey. Chest. 2010;138(5):1093-1100.

20. Gage BF, Yan Y, Milligan PE, et al. Clinical classification schemes for predicting hemorrhage: results from the National Registry of Atrial Fibrillation (NRAF). Am Heart J. 2006;151(3):713-719.

21. Fernández-Barrés S, Martín N, Canela T, et al; Project ATDOM-NUT group. Dietary intake in the dependent elderly: evaluation of the risk of nutritional deficit. J Hum Nutr Diet. Epub 2015 Apr 28. doi: 10.1111/ jhn. 12310 .

22. Connolly SJ, Ezekowitz MD, Yusuf S, et al; RE-LY Steering Committee and Investigators. Dabigatran versus warfarin in patients with atrial fibrillation. N Engl J Med. 2009;361(12):1139-1151.

23. Smythe MA, Forman MJ, Bertran EA, Hoffman JL, Priziola JL, Koerber JM. Dabigatran versus warfarin major bleeding in practice: an observational comparison of patient characteristics, management and outcomes in atrial fibrillation patients. J Thromb Thrombolysis. 2015;40(3):280-287.

24. Patel MR, Mahaffey KW, Garg J, et al; ROCKET AF Investigators. Rivaroxaban versus warfarin in nonvalvular atrial fibrillation. $N$ Engl J Med. 2011;365(10):883-891.

25. Connolly SJ, Eikelboom J, Joyner C, et al; AVERROES Steering Committee and Investigators. Apixaban in patients with atrial fibrillation. N Engl J Med. 2011;364(9):806-817.

26. Granger CB, Alexander JH, McMurray JJ, et al; ARISTOTLE Committees and Investigators. Apixaban versus warfarin in patients with atrial fibrillation. N Engl J Med. 2011;365(11):981-992.

27. Giugliano RP, Ruff CT, Rost NS, et al; ENGAGE AF-TIMI 48 Investigators. Cerebrovascular events in 21105 patients with atrial fibrillation randomized to edoxaban versus warfarin: Effective Anticoagulation with Factor Xa Next Generation in Atrial Fibrillation-Thrombolysis in Myocardial Infarction 48. Stroke. 2014;45(8):2372-2378.

28. Ruff CT, Giugliano RP, Braunwald E, et al. Comparison of the efficacy and safety of new oral anticoagulants with warfarin in patients with atrial fibrillation: a meta-analysis of randomised trials. Lancet. 2014; 383(9921):955-962.

29. Dewilde WJ, Oirbans T, Verheugt FW, et al; WOEST study investigators. Use of clopidogrel with or without aspirin in patients taking oral anticoagulant therapy and undergoing percutaneous coronary intervention: an open-label, randomised, controlled trial. Lancet. 2013; 381(9872):1107-1115.

30. Camm AJ, Kirchhof P, Lip GY, et al; ESC Committee for Practice Guidelines. Guidelines for the management of atrial fibrillation: the Task Force for the Management of Atrial Fibrillation of the European Society of Cardiology (ESC). Europace. 2010;12(10): 1360-1420.

31. Keeling D, Baglin T, Tait C, et al; British Committee for Standards in Haematology. Guidelines on oral anticoagulation with warfarin - fourth edition. Br J Haematol. 2011;154(3):311-324.

32. Block PC, Burstein S, Casale PN, et al. Percutaneous left atrial appendage occlusion for patients in atrial fibrillation suboptimal for warfarin therapy: 5-year results of the PLAATO (Percutaneous Left Atrial Appendage Transcatheter Occlusion) study. JACC Cardiovasc Interv. 2009;2(7):594-600.

33. Reddy VY, Sievert H, Halperin J, et al; PROTECT AF Steering Committee and Investigators. Percutaneous left atrial appendage closure vs warfarin for atrial fibrillation: a randomized clinical trial. JAMA. 2014;312(19):1988-1998.
34. Reddy VY, Möbius-Winkler S, Miller MA, et al. Left atrial appendage closure with the Watchman device in patients with a contraindication for oral anticoagulation: the ASAP study (ASA Plavix Feasibility Study With Watchman Left Atrial Appendage Closure Technology). J Am Coll Cardiol. 2013;61(25):2551-2556.

35. Meier B, Palacios I, Windecker S, et al. Transcatheter left atrial appendage occlusion with Amplatzer devices to obviate anticoagulation in patients with atrial fibrillation. Catheter Cardiovasc Interv. 2003; 60(3):417-422.

36. Nietlispach F, Gloekler S, Krause R, et al. Amplatzer left atrial appendage occlusion: single center 10-year experience. Catheter Cardiovasc Interv. 2013;82(2):283-289.

37. Bartus K, Han FT, Bednarek J, et al. Percutaneous left atrial appendage suture ligation using the LARIAT device in patients with atrial fibrillation: initial clinical experience. J Am Coll Cardiol. 2013;62(2):108-118.

38. Romero J, Natale A, Engstrom K, Di Biase L. Left atrial appendage isolation using percutaneous (endocardial/epicardial) devices: pre-clinical and clinical experience. Trends Cardiovasc Med. Epub 2015 Jun 4.

39. Olshansky B, Rosenfeld LE, Warner AL, et al; AFFIRM Investigators. The Atrial Fibrillation Follow-up Investigation of Rhythm Management (AFFIRM) study: approaches to control rate in atrial fibrillation. $\mathrm{J} \mathrm{Am}$ Coll Cardiol. 2004;43(7):1201-1208.

40. Hallberg P, Lindbäck J, Lindahl B, Stenestrand U, Melhus H; RIKS-HIA group. Digoxin and mortality in atrial fibrillation: a prospective cohort study. Eur J Clin Pharmacol. 2007;63(10):959-971.

41. Aronow WS. Management of atrial fibrillation in the elderly. Minerva Med. 2009;100(1):3-24.

42. Wyse DG. Pharmacotherapy for rhythm management in elderly patients with atrial fibrillation. J Interv Card Electrophysiol. 2009;25(1):25-29.

43. Groenveld HF, Tijssen JG, Crijns HJ, et al; RACE II Investigators. Rate control efficacy in permanent atrial fibrillation: successful and failed strict rate control against a background of lenient rate control: data from RACE II (Rate Control Efficacy in Permanent Atrial Fibrillation). J Am Coll Cardiol. 2013;61(7):741-748.

44. Roy D, Talajic M, Nattel S, et al; Atrial Fibrillation and Congestive Heart Failure Investigators. Rhythm control versus rate control for atrial fibrillation and heart failure. $N$ Engl J Med. 2008;358(25):2667-2677.

45. Podrid PJ, Lampert S, Graboys TB, Blatt CM, Lown B. Aggravation of arrhythmia by antiarrhythmic drugs - incidence and predictors. $\mathrm{Am}$ $J$ Cardiol. 1987;59(11):38E-44E.

46. Stanton MS, Prystowsky EN, Fineberg NS, et al. Arrhythmogenic effects of antiarrhythmic drugs: a study of 506 patients treated for ventricular tachycardia or fibrillation. J Am Coll Cardiol. 1989;14(1):209-215.

47. Echt DS, Liebson PR, Mitchell LB, et al. Mortality and morbidity in patients receiving encainide, flecainide, or placebo. The Cardiac Arrhythmia Suppression Trial. N Engl J Med. 1991;324(12):781-788.

48. Connolly SJ, Camm AJ, Halperin JL, et al; PALLAS Investigators. Dronedarone in high-risk permanent atrial fibrillation. $N$ Engl J Med. 2011;365(24):2268-2276.

49. Calkins H, Kuck KH, Cappato R, et al; Heart Rhythm Society Task Force on Catheter and Surgical Ablation of Atrial Fibrillation. 2012 HRS/EHRA/ECAS expert consensus statement on catheter and surgical ablation of atrial fibrillation: recommendations for patient selection, procedural techniques, patient management and follow-up, definitions, endpoints, and research trial design: a report of the Heart Rhythm Society (HRS) Task Force on Catheter and Surgical Ablation of Atrial Fibrillation. Developed in partnership with the European Heart Rhythm Association (EHRA), a registered branch of the European Society of Cardiology (ESC) and the European Cardiac Arrhythmia Society (ECAS); and in collaboration with the American College of Cardiology (ACC), American Heart Association (AHA), the Asia Pacific Heart Rhythm Society (APHRS), and the Society of Thoracic Surgeons (STS). Endorsed by the governing bodies of the American College of Cardiology Foundation, the American Heart Association, the European Cardiac Arrhythmia Society, the European Heart Rhythm Association, the Society of Thoracic Surgeons, the Asia Pacific Heart Rhythm Society, and the Heart Rhythm Society. Heart Rhythm. 2012;9(4):632-696. e21. 
50. Corrado A, Patel D, Riedlbauchova L, et al. Efficacy, safety, and outcome of atrial fibrillation ablation in septuagenarians. $J$ Cardiovasc Electrophysiol. 2008;19(8):807-811.

51. Wazni OM, Marrouche NF, Martin DO, et al. Radiofrequency ablation vs antiarrhythmic drugs as first-line treatment of symptomatic atrial fibrillation: a randomized trial. JAMA. 2005;293(21):2634-2640.

52. Yamada T, Kay GN. Catheter ablation of atrial fibrillation in the elderly. Pacing Clin Electrophysiol. 2009;32(8):1085-1091.

53. Cappato R, Calkins H, Chen SA, et al. Updated worldwide survey on the methods, efficacy, and safety of catheter ablation for human atrial fibrillation. Circ Arrhythm Electrophysiol. 2010;3(1):32-38.

54. Catanzaro J, Calkins H. An approach to catheter ablation of atrial fibrillation in the elderly. Card Electrophysiol Clin. 2012;4:119-125.

55. Zado E, Callans DJ, Riley M, et al. Long-term clinical efficacy and risk of catheter ablation for atrial fibrillation in the elderly. $J$ Cardiovasc Electrophysiol. 2008;19(6):621-626.

56. Bhargava M, Marrouche NF, Martin DO, et al. Impact of age on the outcome of pulmonary vein isolation for atrial fibrillation using circular mapping technique and cooled-tip ablation catheter. J Cardiovasc Electrophysiol. 2004;15(1):8-13.

57. Kusumoto F, Prussak K, Wiesinger M, Pullen T, Lynady C. Radiofrequency catheter ablation of atrial fibrillation in older patients: outcomes and complications. J Interv Card Electrophysiol. 2009;25(1): 31-35.

58. Tan HW, Wang XH, Shi HF, et al. Efficacy, safety and outcome of catheter ablation for atrial fibrillation in octogenarians. Int J Cardiol. 2010;145(1):147-148.

59. Bunch TJ, Weiss JP, Crandall BG, et al. Long-term clinical efficacy and risk of catheter ablation for atrial fibrillation in octogenarians. Pacing Clin Electrophysiol. 2010;33(2):146-152.

60. Liu Y, Huang H, Huang C, et al; National Atrial Fibrillation Working Group of Chinese Society of Pacing and Electrophysiology. Catheter ablation of atrial fibrillation in Chinese elderly patients. Int J Cardiol. 2011;152(2):266-267.

61. Lioni L, Letsas KP, Efremidis M, et al. Catheter ablation of atrial fibrillation in the elderly. J Geriatr Cardiol. 2014;11(4):291-295.
62. Nademanee K, Amnueypol M, Lee F, et al. Benefits and risks of catheter ablation in elderly patients with atrial fibrillation. Heart Rhythm. 2015; 12(1):44-51.

63. Chao TF, Lin YJ, Chang SL, et al. Can oral anticoagulants be stopped safely after a successful atrial fibrillation ablation? J Thorac Dis. 2015; $7(2): 172-177$.

64. Chierchia GB, Capulzini L, de Asmundis C, et al. Cryoballoon ablation for paroxysmal atrial fibrillation in septuagenarians: a prospective study. Indian Pacing Electrophysiol J. 2010;10(9):393-399.

65. Khan MN, Jaïs P, Cummings J, et al; PABA-CHF Investigators. Pulmonary-vein isolation for atrial fibrillation in patients with heart failure. N Engl J Med. 2008;359(17):1778-1785.

66. Hsieh MH, Tai CT, Lee SH, et al. Catheter ablation for atrial fibrillation versus atrioventricular junction ablation plus pacing therapy for elderly patients with medically refractory paroxysmal atrial fibrillation. J Cardiovasc Electrophysiol. 2005;16(5):457-461.

67. Disertori M, Latini R, Barlera S, et al. Valsartan for prevention of recurrent atrial fibrillation. N Engl J Med. 2009;360(16):1606-1617.

68. Lin TT, Yang YH, Liao MT, et al. Primary prevention of atrial fibrillation with angiotensin-converting enzyme inhibitors and angiotensin receptor blockers in patients with end-stage renal disease undergoing dialysis. Kidney Int. 2015;88(2):378-385.

69. Liu T, Li L, Korantzopoulos P, Liu E, Li G. Statin use and development of atrial fibrillation: a systematic review and meta-analysis of randomized clinical trials and observational studies. Int $J$ Cardiol. 2008;126(2):160-170.

70. Korantzopoulos P, Kolettis TM, Siogas K, Goudevenos JA. The emerging role of inflammation in atrial fibrillation and the potential of antiinflammatory interventions. Eur Heart J. 2005;26(20):2207-2208.

71. Kumar S, Sutherland F, Morton JB, et al. Long-term omega-3 polyunsaturated fatty acid supplementation reduces the recurrence of persistent atrial fibrillation after electrical cardioversion. Heart Rhythm. 2012;9(4):483-491.
Vascular Health and Risk Management

\section{Publish your work in this journal}

Vascular Health and Risk Management is an international, peerreviewed journal of therapeutics and risk management, focusing on concise rapid reporting of clinical studies on the processes involved in the maintenance of vascular health; the monitoring, prevention and treatment of vascular disease and its sequelae; and the involvement of

\section{Dovepress}

metabolic disorders, particularly diabetes. This journal is indexed on PubMed Central and MedLine. The manuscript management system is completely online and includes a very quick and fair peer-review system, which is all easy to use. Visit http://www.dovepress.com/ testimonials.php to read real quotes from published authors. 